\title{
Uncommon IgA lymphoplasmacytic lymphoma: Case report
}

\author{
André Domingues Pereira ${ }^{1,2}$, Elisabetta Sachsida Colombo ${ }^{2}$, Alex Freire Sandes ${ }^{1,3}$, Celso Arrais Rodrigues ${ }^{1,2}$ and Matheus Vescovi Gonçalves ${ }^{1,3}$ \\ ${ }^{1}$ Disciplina de Hematologia e Hemoterapia, Universidade Federal de São Paulo, São Paulo, Brazil \\ ${ }^{2}$ Centro de Oncologia, Hospital Sírio-Libanês, São Paulo, Brazil \\ ${ }^{3}$ Laboratório de Hematolgia, Laboratório Fleury, São Paulo, Brazil
}

\section{Introduction}

Lymphoplasmacytic lymphoma (LPL) is a rare neoplasm of small B lymphocytes with varying degrees of plasmacytic differentiation, usually comprising clonal plasmacytoid lymphocytes and plasma cells, which does not fulfil the criteria for any of the other small B-cell lymphoid neoplasms that can also have plasmacytic differentiation [1]. The immunophenotype usually resembles the normal lymphocytes and plasma cells, except for clonal restriction and CD25+/- and CD138+/expression, differing from the profile of neoplastic myeloma plasma cells, that usually lose CD19 and abnormally express CD56, along with loss of CD45 and CD81, and expression of CD117 [2]. Clinical presentation is highly variable, with symptoms usually related to the cytopenias (mainly anemia) due to bone marrow infiltration [3]. If both bone marrow infiltration and IgM monoclonal gammopathy are present, the disease is called Waldenström Macroglobulinemia (WM), accounting for up to $2 \%$ of all cases of non-Hodgkin lymphoma in the United States and Europe [4]. Non-IgM lymphoplasmacytic lymphoma (LPL) is very rare, comprising less than 5\% of LPLs [5] with no clinical or pathological differences when compared to the more common IgM LPL [6]. Differential diagnosis should include multiple myeloma (MM), chronic lymphocytic leukemia and other non-Hodgkin lymphomas such as splenic or nodal marginal zone lymphomas, as different treatment approaches are recommended.

\section{Case Report}

A previously healthy 74-year-old Chinese female patient living in Northern Brazil had a broken right femur after a moderate trauma, with no other clinical symptoms. Medical examination revealed no lymphadenopathies, or organomegalies. Her hemoglobin was $9 \mathrm{~g} / \mathrm{dL}$, white blood count $16.5 \times 10^{9} / \mathrm{L}$ (neutrophils $15.2 \times 10^{9} / \mathrm{L}$; lymphocytes $0.66 \times 10^{9} / \mathrm{L}$ ) and platelet count $497 \times 10^{9} / \mathrm{L}$. Protein electrophoresis showed a monoclonal peak of $3.89 \mathrm{~g} / \mathrm{dL}$ in the beta region, identified as IgA lambda by immunoelectrophoresis. IgA was $3860 \mathrm{mg} / \mathrm{dL}$, albumin $3.8 \mathrm{~g} / \mathrm{dL}$, ionized calcium $1.21 \mathrm{mM} / \mathrm{L}$ (normal range: $1.15-1.32 \mathrm{mM} / \mathrm{L}$ ) and beta-2 microglobulin $5.9 \mathrm{mg} / \mathrm{L}$ (normal range: $<2,4 \mathrm{mg} / \mathrm{L}$ ).

Computed tomography scans revealed no lytic lesions and a bone marrow (BM) biopsy showed a hypercellular marrow with $80 \%$ infiltration of small/medium sized lymphoid cells. BM immunohistochemistry showed monoclonal B cell lymphocytes, but was not conclusive for diagnosis. A BM aspirate showed $32 \%$ of small to moderate sized lymphoplasmacytoid lymphocytes and $4 \%$ of plasma cells.
Immunophenotyping by 8 -color flow cytometry of the BM showed $28 \%$ of clonal lymphocytes and $3.5 \%$ of clonal plasma cells. Lymphocytes expressed CD19, CD20, FMC-7, heterogeneous CD38, surface IgA, and lambda light chain; they were negative for CD5, CD10 and CD11c. Plasma cells showed a "normal" phenotype, expressing CD38, CD138, CD19, CD45, cytoplasmic IgA, cytoplasmic lambda and no expression of CD56, CD117, CD81, or CD27.

Only one signal of the 6q23 region was observed in 18 of 200 interphases by fluorescent in situ hybridization (FISH). MYD88 presented the typical L265P mutation.

We concluded that the patient presented a high-risk LPL, IgA lambda, according to MW specific IPSS [7](older age, anemia, and high beta- 2 microglobulin). Treatment indications were older age ( $>70$ yearsold) and the presence of anemia [8]. She received 6 cycles of rituximab, cyclophosphamide and dexamethasone (RCD). The monoclonal peak dropped from $3.89 \mathrm{~g} / \mathrm{dL}$ to $0.99 \mathrm{~g} / \mathrm{dL}$, IgA level dropped from $3890 \mathrm{mg} /$ $\mathrm{dL}$ to $695 \mathrm{mg} / \mathrm{dL}$, and hemoglobin level normalized, characterizing partial response. She has finished 2-year maintenance with rituximab and remains in partial remission, with no disease-related symptoms. Monoclonal pike is currently $0.61 \mathrm{~g} / \mathrm{dL}$ and $\mathrm{IgA}$ is $332 \mathrm{mg} / \mathrm{dL}$.

\section{Discussion}

In the present case, an expressive monoclonal peak of more than $3 \mathrm{~g} / \mathrm{dL}$ in a patient with mild anemia and no other MM clinical features raised the suspicion of a non-IgM LPL. Bone marrow immunophenotyping and the presence of MYD88 L265P mutation confirmed the diagnosis.

Non-IgM LPL is a rare disease and the precise diagnosis could be challenging. While IgM gammopathy is associated with LPL, IgA or IgG are more common in MM [9]. However, clinical presentation is similar to $\mathrm{MM}$, with bone lesions, hypercalcemia and renal insufficiency, rarely observed in LPL [10]. Less frequently, IgA or IgG gammopathy might be associated with other non-Hodgkin lymphoma such as splenic or

*Correspondence to: André Domingues Pereira, Disciplina de Hematologia e Hemoterapia, Universidade Federal de São Paulo, São Paulo, Brazil, E-mail: andredompereira@yahoo.com.br

Key words: Non-IgM lymphoplasmacytic lymphoma, diagnosis, immunophenotyping, MYD88 L265P mutations

Received: January 20, 2019; Accepted: January 28, 2019; Published: January 31,2019 
nodal marginal zone lymphomas, and chronic lymphocytic leukemia. For a definite diagnosis, it is essential to perform a thorough analysis of the morphology and the immunophenotype, as well as the confirmation of clonality [4].

There are no specific chromosomal aberrations in LPL but $6 \mathrm{q}$ deletion is the most common, present in $30 \%$ of patients, and may be associated with worse prognosis [11]. MYD88 L265P mutation is present in about $90 \%$ of WM and has become a new tool for diagnosis. In non-IgM LPL the mutation is less common, occurring in about $40 \%$ of patients in two case series [5,6]. Besides, it is rarely present in marginal-zone lymphomas and is absent in MM [12].

\section{Conclusion}

In conclusion, our case illustrates that the presence of $\operatorname{IgA}$ paraprotein should be carefully investigated, and the differential diagnosis should include LPL. The lack of MM features, such as bone lytic lesions or hypercalcemia, the specific immunophenotype along with MYD88 L265P mutation favored LPL. MYD88 L265P mutation is a very helpful tool to a more precise diagnosis of WM.

\section{References}

1. Swerdlow SH, Berger F, Pileri SA (2008) Lymphoplasmacytic lymphoma. In: Swerdlow SH, Campo E, Harris NL (Eds). WHO Classification of Tumours of Haematopoietic and Lymphoid Tissues. (4th Edn) IARC: Lyon, France, pp. 194-195.

2. Konoplev S, Medeiros LJ, Bueso-Ramos CE, Jorgensen JL, Lin P (2005) Immunophenotypic profile of lymphoplasmacytic lymphoma/Waldenström macroglobulinemia. Am J Clin Pathol 124: 414-420. [Crossref]
3. Björkholm M, Johansson E, Papamichael D (2003) Patterns of clinical presentation, treatment, and outcome in patients with Waldenström's macroglobulinemia: a twoinstitution study. Semin Oncol 30: 226-230.

4. Castillo JJ, Garcia-Sanz R, Hatjiharissi E (2016) Recommendations for the diagnosis and initial evaluation of patients with Waldenström Macroglobulinaemia: A Task Force from the 8th International Workshop on Waldenström Macroglobulinaemia $\mathrm{Br}$ J Haematol 175: 77-86.

5. Cao X, Medeiros LJ, Xia Y, Wang X, Thomas SK, et al. (2016) Clinicopathologic features and outcomes of lymphoplasmacytic lymphoma patients with monoclonal IgG or IgA paraprotein expression. Leuk Lymphoma 57: 1104-1113. [Crossref]

6. King RL, Gonsalves WI, Ansell SM, Greipp PT, Frederick LA, et al. (2016) Lymphoplasmacytic Lymphoma With a Non-IgM Paraprotein Shows Clinical and Pathologic Heterogeneity and May Harbor MYD88 L265P Mutations. Am J Clin Pathol 145: 843-851. [Crossref]

7. Morel P, Duhamel A, Gobbi P (2009) International prognostic scoring system for Waldenström Macroglobulinemia. Blood 113: 4163-4170.

8. Leblond V, Kastritis E, Advani R (2016) Treatment recommendations from the Eighth International Workshop on Waldenström's Macroglobulinemia. Blood 128: 1321-1328.

9. Kyle RA, Larson DR, Therneau TM, Dispenzieri A, Kumar S, et al. (2018) Long-Term Follow-up of Monoclonal Gammopathy of Undetermined Significance. $N$ Engl J Med 378: 241-249. [Crossref]

10. Schuster SR, Rajkumar SV, Dispenzieri A, Morice W, Aspitia AM, et al. (2010) IgM multiple myeloma: disease definition, prognosis, and differentiation from Waldenstrom's macroglobulinemia. Am J Hematol 85: 853-855. [Crossref]

11. Nguyen-Khac F, Lambert J, Chapiro E (2013) Chromosomal aberrations and their prognostic value in a series of 174 untreated patients with Waldenström's macroglobulinemia. Haematologica 98: 649-654.

12. Treon SP, Xu L, Yang G, Zhou Y, Liu X, et al. (2012) MYD88 L265P somatic mutation in Waldenström's macroglobulinemia. N Engl J Med 367: 826-833. [Crossref]

Copyright: (C2019 Pereira AD. This is an open-access article distributed under the terms of the Creative Commons Attribution License, which permits unrestricted use, distribution, and reproduction in any medium, provided the original author and source are credited. 